\title{
Effect of repeated heating on thermal behavior of crude palm oil
}

\begin{abstract}
Thermal behavior of crude palm oil (CPO) is important to determine the optimal fractionation process and product yield. In this study, the effects of repeated heating on thermal behavior of $\mathrm{CPO}$ were examined by differential scanning calorimetry. $\mathrm{CPO}$ was heated at $80^{\circ} \mathrm{C}$ for 5 min, and heating was repeated five times to simulate the common conditions experienced by an oil before reaching the refinery. The result revealed that the thermal behavior of CPO changed after heating. The change, however, occurred only in the behavior of the highmelting stearin peak but not in the low-melting olein peak. Overheating split the stearin peak at $17.30^{\circ} \mathrm{C}$ to two peaks at 18.88 and $17.30^{\circ} \mathrm{C}$ and formed a new peak at $11.28^{\circ} \mathrm{C}$. Apparently, a new substance has been synthesized.
\end{abstract}

Keyword: CPO; DSC; Fractionation; Repeated heating; Thermal behavior 